\title{
COMPARISON OF THE DYNAMIC CHANGES OF AMINO ACID BLOOD PLASMA SPECTRUM IN PATIENTS WITH THE PRIMARY CEREBRAL ISCHEMIC STROKE DEPENDING ON THE POSTAPOPLECTIC SPASTICITY DEVELOPMENT IN THE RECOVERY PERIOD
}

\author{
Anzhelika Payenok \\ Department of neuropathology and neurosurgery FPGE \\ Danylo Halytsky Lviv National Medical University \\ 69 Pekarska str., Lviv, Ukraine, 79010 \\ Maria Bilobryn \\ Department of neuropathology and neurosurgery FPGE \\ Danylo Halytsky Lviv National Medical University \\ 69 Pekarska str., Lviv, Ukraine, 79010 \\ Iryna Mitelman \\ Department of neuropathology and neurosurgery FPGE \\ Danylo Halytsky Lviv National Medical University \\ 69 Pekarska str., Lviv, Ukraine, 79010 \\ irina.bh@mail.ru
}

\begin{abstract}
The aim of research was to reveal the dynamic changes of the level of excitatory and inhibitory neuroamino acids in patients with the primary cerebral ischemic stroke depending on postapoplectic spasticity presence at the end of the early recovery period.

For this aim was studied the concentration of excitatory and inhibitory neuroamino acids in the blood plasma in first 72 hours in 97 patients with the primary ischemic cerebral stroke depending on postapoplectic spasticity on the sixth month after ischemic event. The control group included 15 patients with diagnosed chronic cerebral ischemia.

In the result of research we revealed that the common sign for the two groups (with spasticity on the sixth month and without it) was the reliable rise of the level of excitatory amino acids comparing with the control. In patients without spasticity the heightened level of excitatory neurotransmitters in the most acute period of ischemic cerebral stroke was attended with the heightened level of inhibitory neuroamino acids. The distinctive feature of patients with postapoplectic spasticity was the decreased or stable level of transmitters of inhibitory action. During $6^{\text {th }}$ moth after ischemic stroke was detected the rise of all studied neuroamino acids in patients with spasticity unlike to the ones without spasticity who were characterized only with the rise of taurine level and decrease of glycine and aspartate levels.

So, the received results allow assume the insufficient activation of the inhibitory neuroamino acids system in the most acute period of the ischemic stroke in certain category of patients that in future are inclined to the spasticity development after stroke.

Keywords: primary cerebral ischemic stroke, excitatory and inhibitory neurotransmitters, most acute period, early recovery period, postapoplectic spasticity.
\end{abstract}

\section{Introduction}

Last few years the results of numerous researches proved the significant role of excitatory neuroamino acids in the acute and delayed destruction of neurons [1]. The information from the literature data about amino acid spectrum of the blood of patients with the acute ischemic stroke is insufficient and full of contradictions. Thus, in the study of Butter Th. et al. [2] the authors revealed the rise of glutamate concentration in the first 24 hours after ischemic stroke with its further decrease that was not observed at the study of glycine level. Some authors state that the decrease of glutamate level in blood plasma connected with the compensatory rise of GABA at the increased aspartate level [3]. Several researchers proved the rise of glutamate acid level and decrease of glycine and proline levels in patients in the acute period of ischemic stroke [4, 5]. 
In $40 \%$ of synapses of brain and spinal cord the main transmitters are excitatory amino acids aspartate and glutamate [6-8]. In the both pyramidal and cerebellar tracts are present the glutamatergic neurons [9]. The main inhibitory transmitter of CNS is GABA. GABA-ergic influence on the spinal motor centers is realized through the red kernel spinal, vestibular spinal tracts $[6,10]$.

The main inhibitory spinal transmitter is glycine [11-13]. The significant role in spasticity development belongs also to the blue spot - descendent monoaminoergic system where commence the descendent norandrenergic fibers that go in the content of pyramidal tract and end in the grey substance of the spinal cord on the motoneurons of the front horns [14, 15].

The Frosini's et al. research and other ones carried out by the American scientists $[16,17]$ disclosed the certain type of receptors familiar by the biochemical structure to the taurine compound (GABA, glutamate, glycine) that have neither agonistic nor antagonistic effect. That is why such type of receptors is considered as taurine receptors and taurine as such as the inhibitory neurotransmitter.

Taking into account the multi-vector of the scientific data about the content of neurotransmitters in the blood plasma of patients with ischemic stroke and the aforesaid information about their influence of the formation of spastic muscular hypertonus the subject of research is the content of excitatory (glutamate, glutamine acid, aspartate, aspartic acid and tyrosine as the predecessor of noradrenalin) and inhibitory (GABA, glycine, taurine) amino acids of the blood plasma of patients with the primary ischemic stroke depending on the postapoplectic spasticity in the early recovery period.

\section{Aim of research}

To study the dynamic changes of the level of excitatory and inhibitory neuroamino acids in patients with the primary cerebral ischemic stroke depending on the presence of postapoplectic spasticity at the end of the early recovery period.

\section{Materials and methods}

There were examined 97 patients with ischemic stroke in the most acute period (1-3 day) and at the end of the early recovery (sixth month) period, which were at the stationary treatment in $1^{\text {st }}$ and 2 neurological departments of the Municipal city clinical hospital of the Lviv ambulance. The ischemic stroke was diagnosed in all patients using computed tomography. Among patients were 51 men and 46 women, mean age was 60,13 $\pm 0,92$ years (mean age for men- 60,62 $\pm 1,38$, for women $-59,58 \pm 1,21$ years). The muscular tonus was assessed on the $6^{\text {th }}$ month after ischemic stroke using the modified Ashworth scale according to which (taking into account the common rules of its use) the tonus rise at MAS $\geq 1$ is considered as spasticity [18]. Depending on presence of postapoplectic spasticity at the end of the early recovery period 2 groups of patients were formed. The group of patients with spasticity included 48 patients (in 32 ones was revealed the spasticity on hemitype and in 16 the spasticity was only in hand) and the group of patients without spasticity 49 persons. The group of control was formed by 15 patients with the chronic ischemia of brain (8 men and 7 women). The mean age of patients of the control group was $60,27 \pm 1,82$ (mean age for men was $59,75 \pm 2,81$, for women $-60,86 \pm 2,41$ ).

For the study was taken $5 \mathrm{ml}$ of blood from the cubital vein two-time fasting: during the first 72 hours after the primary ischemic stroke and on the $6^{\text {th }}$ month - at the end of the early recovery period. For studying the amino acid blood spectrum was taken plasma and measured the concentration using the automatic amino acid analyzer LC 6001 Biotronic (Germany). The study of neuroamino acids concentration was carried out in laboratory of the molecular biology and clinical biochemistry of the Lviv institute of animal biology.

The statistical processing of data was carried out using the «Excel» program from Windows 2007 package and «Statistica-10» program using the methods of describing statistics for calculation of the median, lower and upper quartiles and determination of the reliable difference for non-parametric values by the Mann-Whitney method. The results were presented as Me [LQ; UQ]. The data were considered as the reliable ones at $\mathrm{p}<0,05$. 


\section{Results}

In the Table 1 are presented the data of the content of excitatory and inhibitory neurotransmitters in the blood plasma of patients with the ischemic stroke in the most acute period and the content of the same amino acids in the control group. Patients with the ischemic stroke were divided in two groups depending on formation of postapoplectic spasticity on the $6^{\text {th }}$ month after acute ischemic event.

\section{Table 1}

Neuroamino acid concentration in patients in the most acute period of PCIS with spasticity on the $6^{\text {th }}$ month and without it

\begin{tabular}{|c|c|c|c|}
\hline \multirow{2}{*}{ Parameter } & \multicolumn{3}{|c|}{ Group of patients } \\
\hline & Control group & Without spasticity & With spasticity \\
\hline Glutamate, mcM/1 & $82,1[75,5 ; 87,7]$ & $\begin{array}{c}173,3[144,3 ; 210,0] \\
\mathrm{p}_{0}<0,01\end{array}$ & $\begin{array}{c}240,8[205,0 ; 285,1] \\
\mathrm{p}_{0}<0,01 \\
\mathrm{p}_{1}<0,01\end{array}$ \\
\hline Glutamine, mcM/1 & $487,9[430,3 ; 510,8]$ & $\begin{array}{c}505,3[480,1 ; 520,4] \\
\mathrm{p}_{0}>0,05\end{array}$ & $\begin{array}{c}1087,9[950,1 ; 1309,8] \\
\mathrm{p}_{0}<0,01 \\
\mathrm{p}_{1}<0,01\end{array}$ \\
\hline Aspartate, mcM/l & $153,2[143,1 ; 168,2]$ & $\begin{array}{c}215,7[197,5 ; 235 ; 1] \\
\mathrm{p}_{0}<0,01\end{array}$ & $\begin{array}{c}321,2[287,5 ; 342,7] \\
\mathrm{p}_{0}<0,01 \\
\mathrm{p}_{1}<0,01\end{array}$ \\
\hline Asparagine, mcM/1 & $53,6[49,6 ; 57,9]$ & $\begin{array}{c}66,8[58,3 ; 75,6] \\
\mathrm{p}_{0}<0,05\end{array}$ & $\begin{array}{c}56,6[54,5 ; 58,7] \\
\mathrm{p}_{0}>0,05 \\
\mathrm{p}_{1}<0,01\end{array}$ \\
\hline Tyrosine, mcM/1 & $54,7[50,1 ; 59,9]$ & $\begin{array}{c}49,6[41,2 ; 52,4] \\
\mathrm{p}_{0}<0,01\end{array}$ & $\begin{array}{c}46,7[40,3 ; 50,8] \\
\mathrm{p}_{0}<0,01 \\
\mathrm{p}_{1}>0,05\end{array}$ \\
\hline $\mathrm{GABA}, \mathrm{mcM} / 1$ & $2,8[2,5 ; 3,4]$ & $\begin{array}{c}10,0[8,7 ; 11,7] \\
\mathrm{p}_{0}<0,01\end{array}$ & $\begin{array}{c}3,4[2,6 ; 4,1] \\
\mathrm{p}_{0}>0,05 \\
\mathrm{p}_{1}<0,01\end{array}$ \\
\hline Glycine, mcM/1 & $185,0[178,3 ; 189,9]$ & $\begin{array}{c}277,8[245,7 ; 301,7] \\
\mathrm{p}_{0}<0,05\end{array}$ & $\begin{array}{c}70,1[55,8 ; 81,1] \\
\mathrm{p}_{0}<0,01 \\
\mathrm{p}_{1}<0,01\end{array}$ \\
\hline Taurine, mcM/1 & $27,9[24,7 ; 30,3]$ & $\begin{array}{c}17,0[16.2 ; 18,7] \\
\mathrm{p}_{0}<0,05\end{array}$ & $\begin{array}{c}13,6[12,1 ; 15,6] \\
\mathrm{p}_{0}<0,05 \\
\mathrm{p}_{1}<0,05\end{array}$ \\
\hline Glutamate/GABA & $30,0[21,9 ; 34,1]$ & $\begin{array}{c}17,1[14,7 ; 19,9] \\
\mathrm{p}_{0}<0,01\end{array}$ & $\begin{array}{c}74,5[55,7 ; 102,7] \\
\mathrm{p}_{0}<0,01 \\
\mathrm{p}_{1}<0,01\end{array}$ \\
\hline
\end{tabular}

Notes: $p_{0}$ - probability of differences comparing with the control group; $p_{1}$ - probability of differences comparing with patients without postapoplectic spasticity

In the Table 2 are presented the excitatory and inhibitory neuroamino acids in the blood plasma at the end of the early recovery period depending on presence of postapoplectic spasticity. 
Table 2

Neuroamino acids concentration in patients in the PCIS recovery period with spasticity on the $6^{\text {th }}$ month and without it

\begin{tabular}{|c|c|c|c|}
\hline \multirow{2}{*}{ Parameter } & \multicolumn{3}{|c|}{ Group of patients } \\
\hline & Control group & Without spasticity & With spasticity \\
\hline Glutamate, mcM/1 & $82,1[75,5 ; 87,7]$ & $\begin{array}{c}86,7[83,7 ; 91,7] \\
\mathrm{p}_{0}>0,05\end{array}$ & $\begin{array}{c}168,3[157,9 ; 199,3] \\
\mathrm{p}_{0}<0,01 \\
\mathrm{p}_{1}<0,01\end{array}$ \\
\hline Glutamine, mcM/1 & $487,9[430,3 ; 510,8]$ & $\begin{array}{c}500,1[480,8 ; 510,4] \\
\mathrm{p}_{0}>0,05\end{array}$ & $\begin{array}{c}693,6[551,5 ; 755,4] \\
\mathrm{p}_{0}<0,01 \\
\mathrm{p}_{1}<0,05\end{array}$ \\
\hline Aspartate, mcM/l & $153,2[143,1 ; 168,2]$ & $\begin{array}{c}105,8[91,1 ; 123,2] \\
\mathrm{p}_{0}<0,01\end{array}$ & $\begin{array}{c}189,7[166,2 ; 237,8] \\
\mathrm{p}_{0}<0,05 \\
\mathrm{p}_{1}<0,01\end{array}$ \\
\hline Asparagine, mcM/l & $53,6[49,6 ; 57,9]$ & $\begin{array}{c}72,5[65,9 ; 80,2] \\
\mathrm{p}_{0}<0,01\end{array}$ & $\begin{array}{c}65,2[59,8 ; 70,6] \\
\mathrm{p}_{0}<0,05 \\
\mathrm{p}_{1}<0,05\end{array}$ \\
\hline Tyrosine, mcM/1 & $54,7[50,1 ; 59,9]$ & $\begin{array}{c}58,8[53,2 ; 62,3] \\
\mathrm{p}_{0}>0,05\end{array}$ & $\begin{array}{c}79,9[77,3 ; 87,6] \\
\mathrm{p}_{0}<0,05 \\
\mathrm{p}_{1}<0,05\end{array}$ \\
\hline $\mathrm{GABA}, \mathrm{mcM} / 1$ & $2,8[2,5 ; 3,4]$ & $\begin{array}{c}3,3[2,7 ; 3,8] \\
\mathrm{p}_{0}>0,05\end{array}$ & $\begin{array}{c}11,5[9,5 ; 13,0] \\
\mathrm{p}_{0}<0,01 \\
\mathrm{p}_{1}<0,01\end{array}$ \\
\hline Glycine, $\mathrm{mcM} \backslash 1$ & $185,0[178,3 ; 189,9]$ & $\begin{array}{c}120,2[107,7 ; 157,9] \\
\mathrm{p}_{0}<0,05\end{array}$ & $\begin{array}{c}232,7[193,1 ; 302,7] \\
\mathrm{p}_{0}<0,01 \\
\mathrm{p}_{1}<0,01\end{array}$ \\
\hline Taurine, mcM/l & $27,9[24,7 ; 30,3]$ & $\begin{array}{c}82,1[75,5 ; 87,8] \\
\mathrm{p}_{0}<0,01\end{array}$ & $\begin{array}{c}53,9[44,7 ; 70,2] \\
\mathrm{p}_{0}<0,01 \\
\mathrm{p}_{1}<0,05\end{array}$ \\
\hline Glutamate/GABA & $30,0[21,9 ; 34,1]$ & $\begin{array}{c}25,9[22,3 ; 32,6] \\
\mathrm{p}_{0}>0,05\end{array}$ & $\begin{array}{c}16,8[12,7 ; 19,8] \\
\mathrm{p}_{0}<0,01 \\
\mathrm{p}_{1}<0,01\end{array}$ \\
\hline
\end{tabular}

Notes: $p_{0}$ - probability of differences comparing with the control group; $p_{1}$ - probability of differences comparing with patients without postapoplectic spasticity

\section{Discussion of the results of research}

At comparison of the level of excitatory neurotransmitters in the most acute period of PCIS the common sign for two groups of patients with postapoplectic spasticity in the one group of muscles on the $6^{\text {th }}$ month and without it was revealed the reliable increase of glutamate $(p<0,01)$ and aspartate $(p<0,01)$ levels comparing with the control group (Table 1). At that in the group of patients with spasticity the concentration of these neurotransmitters grew mainly with exceed by $32 \%$ as to glutamate level and by $33 \%$ - aspartate one. The common sign for two groups of patients was also the reliable decrease of tyrosine level $(p<0,01)$ comparing with the control group. The distinctive feature in the group of patients with PAS was the significantly higher concentration of glutamine level and as opposite to the group of patients without spasticity it was the statistically significant difference comparing with the control group $(\mathrm{p}<0,01)$. An interesting feature was the fact that unlike patients with spasticity on the $6^{\text {th }}$ month after PCIS in the group of patients without 
spasticity the asparagine level mainly increased and it was statistically reliably comparing with the control group $(\mathrm{p}<0,05)$ (Table 1).

It must be noted that in the most acute period of PCIS were revealed also the differences as to the inhibitory neurotransmitters concentration between the group of patients with spasticity on the $6^{\text {th }}$ month and without it. Thus, in patients without PAS the GABA level grew much more significantly and exceeded concentration in 2,9 times comparing with the control group $(\mathrm{p}<0,01)$, while in the group of patients with PAS the exceed of the level of control group was in 1,3 times $(p>0,05)$. An interesting feature was the difference of the glycine level which concentration in the group of patients without PAS had the tendency to increase and exceeded the value of the control group by $49 \%(p>0,05)$, and in the group of patients with PAS reliably decreased as to the group of control $(p<0,01)$ and group of patients with spasticity $(p<0,01)$. The taurine level in the most acute period of stroke was reliably decreased in both groups of patients $(p<0,05)$. The generalized results of the study of excitatory and inhibitory neurotransmitters level in the most acute period of ischemic stroke are presented in the Table 1.

During the $6^{\text {th }}$ month after PCIS the reliably higher level of excitatory neuroamoni acids was revealed in patients with PAS comparing with patients without spasticity and the control group. So, the glutamate level measured in patients with PAS exceeded the values in patients without spasticity by $95 \%(\mathrm{p}<0,01)$, glutamine - by $38 \%(\mathrm{p}<0,05)$ aspartate by $80 \%(\mathrm{p}<0,01)$ tyrosine by $36 \%$ $(\mathrm{p}<0,05)$. The single exception is the value of asparagine content which level was by $11 \%$ higher in the group of patients without spasticity $(p<0,05)$. At the same time the glutamate, glutamine and tyrosine concentration in patients without spasticity did not have the statistically significant difference comparing with the control $(\mathrm{p}>0,05)$. In the same group of patients the revealed aspartate level was reliably higher than in the control one and asparagine level was lower, so, we can make a conclusion about the activation of process of aspartate biotransformation into asparagine in these patients [19] (Fig. 1).

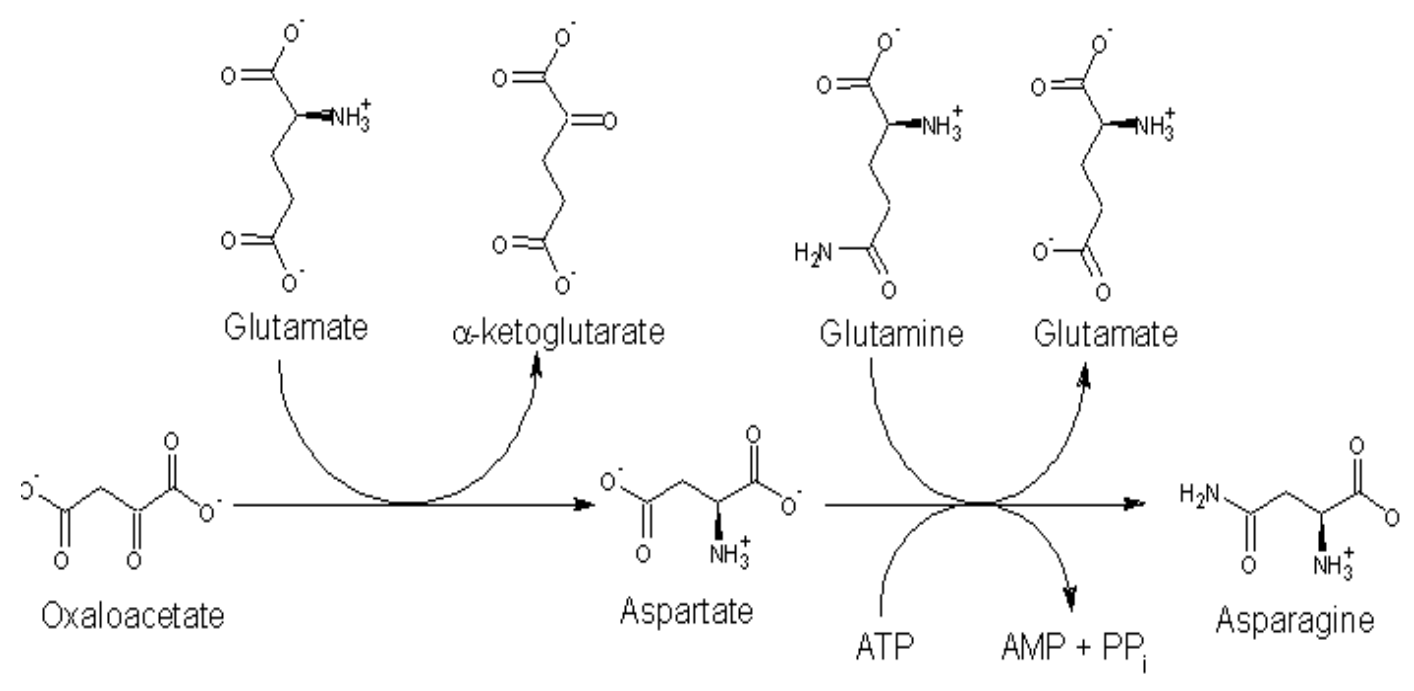

transaminase

asparagine synthetase

Fig. 1. Asparagine biosynthesis

As to the concentration of inhibitory neurotransmitters must be noted the significantly higher values of GABA and glycine levels in patients with spasticity that was statistically significant comparing with group without PAS ( $p<0,01$ for glutamate and glycine) and the control one ( $<<0,01$ for glutamate and glycine). In patients without spasticity the GABA concentration did not statistically differ from the control value and glycine level was reliably lower $(p<0,05)$. Taurin was characterized with an increase of its level in both groups comparing with control but unlike GABA and glycine its concentration was higher in patients without spasticity. Taking into account the glutamatelGABA ratio, it must be noted, that its value in patients without spasticity did not reliably differ 
from the one in the control group ( $p>0,05)$, and in patients with PAS it was lower comparing with the control value, that was statistically significant $(p<0,01)$. The results of the study of excitatory and inhibitory neurotransmitters level at the end of the early recovery period of ischemic stroke are presented in the Table 2.

So, the analysis of the received data demonstrated the activation of excitatory neurotransmitters system in both groups on 1-3 day after ischemic stroke and decrease of activity of the inhibitory transmitters system in patients with PAS at the end of the early recovery period. In the group of patients without spasticity in any muscular group took place an activation of the inhibitory transmitters (GABA, glycine) system as a response on the surplus concentration of excitatory neuroamino acids. Taking into account the received results and biochemical features of GABAbypass [20] (Fig. 2) we can make an assumption about the certain compensatory mechanisms of biotransformation of the glutamate surplus into GABA in certain category of patients with ischemic stroke that to some extent prevent the spasticity development.

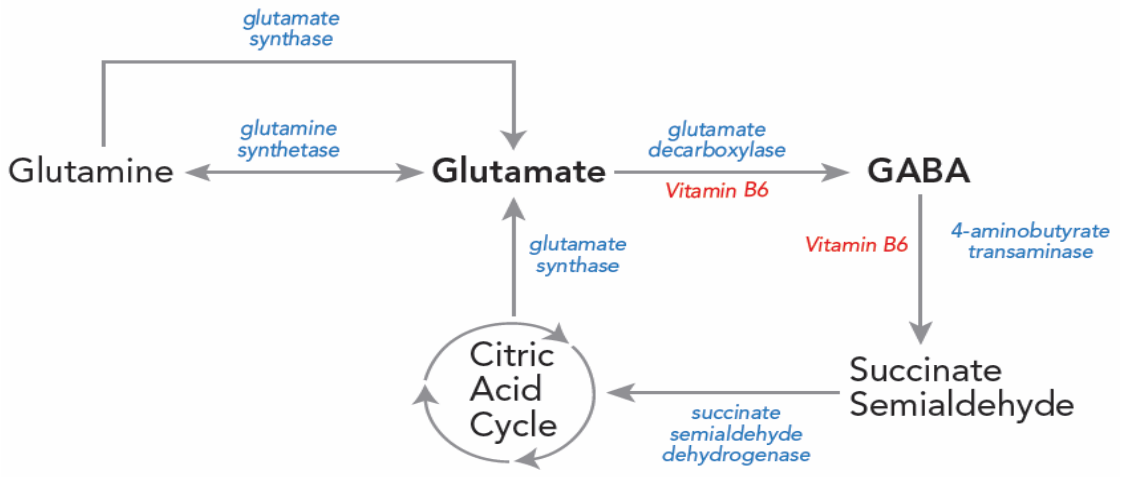

Fig. 2. GABA-bypass

So, if calculate the glutamate/GABA ration, in the control group it was $30,0[21,9 ; 34,1]$, and in the group of patients with PAS and without it 74,5 [55,7; 102,7] and 17,1 [14,7; 19,9] respectively, that was statistically significant comparing with the control group $(p<0,01)$ and between two groups of patients who underwent PCIS $(p<0,01)$. Summing up the results received during the $6^{\text {th }}$ month after stroke we can make a conclusion about the presence of "neurotransmitter strain" in patients with developed postapoplectic spasticity.

\section{Conclusions}

1. The revealed insufficiency of the amino acid inhibitory system in the most acute period of ischemic stroke in the certain category of patients who in the further were inclined to the spasticity development can be used for the screening of such patients for the early rehabilitation.

2. The research needs the special attention for the further study of the possibility of correction of insufficiency of the inhibitory neuroamino acids system in the most acute period of ischemic stroke in patients who need it.

3. The revealed differential features of the neuroamino acid spectrum of blood plasma of patients in the most acute period of stroke can be used for elaboration of the model of prognostication of the postapoplectic spasticity formation.

\section{References}

[1] Skvorzova, V. I., Raevskiy, K. S., Kovalenko, A. V. (2006). Contents of neurotransmitter amino acids in cerebrospinal fluid of ischemic stroke patietn's. Korsakov journal of neurology and psychiatry, 99 (2), 34-38.

[2] Butter, Th., Meves, S., Schute, W. et. al (2008). Temporal profile of excitotoxic amino acids plasma concentrations following acute ischemic infarction. Cerebrovas. Dis., 8 (4), 79.

[3] Dietrich, W. D., Globus, M. Y. T. (Eds.) (1992). The role of neurotransmitters in brain injury. Springer science + business media LLC, New York, 378. doi: 10.1007/978-1-4615-3452-5 
[4] Gusev, E. I., Skvorzova, V. I. (2002). Neurotransmission of glutamate and Ca2+ metabolism in normal condition and associated with cerebral ischemia. Uspehi fiziologicheskih nauk, 33 (4), 80-93.

[5] Castillo, J., Davalos, A., Naveiro, J., Noya, M. (1996). Neuroexcitatory Amino Acids and Their Relation to Infarct Size and Neurological Deficit in Ischemic Stroke. Stroke, 27 (6), 1060-1065. doi: 10.1161/01.str.27.6.1060

[6] Chesselet, M. F., Delfs, J. M. (2011). Trends Neurosci., 19, 417-418.

[7] Herring, B. E., Silm, K., Edwards, R. H., Nicoll, R. A. (2015). Is Aspartate an Excitatory Neurotransmitter? Journal of Neuroscience, 35 (28), 10168-10171. doi: 10.1523/jneurosci.0524-15.2015

[8] Glutamate-Related Biomarkers in Drug Development for Disorders of the Nervous System (2011). doi: 10.17226/13146

[9] Niciu, M. J., Kelmendi, B., Sanacora, G. (2012). Overview of glutamatergic neurotransmission in the nervous system. Pharmacology Biochemistry and Behavior, 100 (4), 656-664. doi: 10.1016/j.pbb.2011.08.008

[10] Cocchiarella, A., Downev, I. A., Darling, R. C. (1967). Evaluation of the effect of diazepam on spasticity. Arch. Phys. Med. Rehabil., 48, 393-396.

[11] Ben Best. Brain Neurotransmitters. Available at: http://www.benbest.com/science/anatmind/ anatmd10.html\#glutamate

[12] López-Corcuera, B., Geerlings, A., Aragón, C. (2001). Glycine neurotransmitter transporters: an update. Molecular Membrane Biology, 18 (1), 13-20. doi: 10.1080/09687680010028762

[13] Bowery, N. G., Smart, T. G. (2009). GABA and glycine as neurotransmitters: a brief history. British Journal of Pharmacology, 147 (S1), S109-S119. doi: 10.1038/sj.bjp.0706443

[14] Davis, L. E., Pirio, S. (2015). Fundamentals of Neurologic Disease. doi: 10.1007/978-1-4939-2359-5

[15] Rank, M. M., Li, X., Bennett, D. J., Gorassini, M. A. (2007). Role of Endogenous Release of Norepinephrine in Muscle Spasms After Chronic Spinal Cord Injury. Journal of Neurophysiology, 97 (5), 3166-3180. doi: 10.1152/jn.01168.2006

[16] Voerman, G., Gregorič, M., Hermens, H. (2005). Neurophysiological methods for the assessment of spasticity: The Hoffmann reflex, the tendon reflex, and the stretch reflex. Disability and Rehabilitation, 27 (1-2), 33-68. doi: 10.1080/09638280400014600

[17] Watkins, C., Leathley, M., Gregson, J., Moore, A., Smith, T., Sharma, A. (2002). Prevalence of spasticity post stroke. Clinical Rehabilitation, 16 (5), 515-522. doi: 10.1191/0269215502cr512oa

[18] Sunnerhagen, K. S., Olver, J., Francisco, G. E. (2013). Assessing and treating functional impairment in poststroke spasticity. Neurology, 80 (3), S35-S44. doi: 10.1212/wnl.0b013e3182764aa2

[19] Volker F. Wendisch, Alexsander Steinbuchel (2009). Amino Acid Biosynthesis - Pathways, regulation and Metabolic Engineering. Schmidt and Vockler GbR, Leipzig, Germany.

[20] Wendisch, V. F. (Ed.) (2007). Amino Acid Biosynthesis Pathways, Regulation and Metabolic Engineering. Microbiology Monographs. doi: 10.1007/978-3-540-48596-4

[21] Donald, P., George, S., Scott, B. (Eds.) (2012). Basic neurochemistry. American society for neurochemistry, Elsevier, 1016. 